
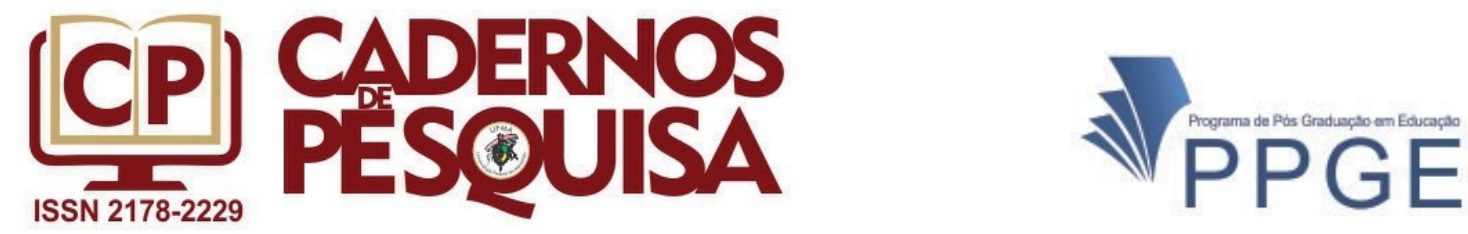

\title{
TECENDO HISTÓRIAS... ENTRELAÇANDO NARRATIVAS... TECITURAS QUE CONSTROEM A DOCÊNCIA DE PROFESSORES BACHARÉIS
}

\author{
WEAVING STORIES... INTERLACING NARRATIVES... WEAVINGS THAT \\ CONSTRUCT THE TEACHING OF BACHELOR TEACHERS
}

\section{TEJER HISTORIAS... ENTRELAZANDO NARRATIVAS: TECITURAS QUE CONSTRUEN LA DOCENCIA DE PROFESORES LICENCIADOS}

\author{
Julia Bolssoni Dolwitsch \\ iD 0000-0002-1586-2311 \\ Helenise Sangoi Antunes \\ iD 0000-0001-6503-658X
}

\section{Resumo}

Este artigo tem como objetivo compreender as trajetórias de vida de professores bacharéis egressos do Programa Especial de Graduação de Formação de Professores para a Educação Profissional (PEG) a fim de investigar os processos formativos que levaram à construção da docência. Os professores investigados participaram de estudo doutoral que buscou apoio metodológico na pesquisa (auto)biográfica, utilizando como metodologia a investigação biográfico-narrativa e fazendo uso de entrevistas narrativas e diário de campo como instrumentos para a produção das informações. $\mathrm{O}$ processo de análise foi pautado pela análise narrativa e produziu dois "movimentos": o primeiro envolveu a reconstrução das trajetórias de vida como textos narrativos, compondo tramas; o segundo fez surgir a "imagem" do "tear biográfico", um dispositivo que impulsionou o entrelaçamento das tramas, possibilitando a composição de tecituras que constroem a docência dos sujeitos da pesquisa. Compreendemos, dessa forma, que a construção da docência não tem uma definição exata, sendo construída nos percursos vividos pelos sujeitos, nos modos de escritas de si e no entrelaçar das tramas, por meio do "tear biográfico". Tramas que carregam muitas histórias, muitas memórias e que ao serem entrelaçadas, produziram tecituras - representações, sentidos e saberes - que, neste trabalho, não são entendidas como aspectos fragmentados, mas sim como aspectos que se articulam no movimento de narrar a vida, definindo a docência de quatro professores bacharéis egressos do PEG.

Palavras chave: Formação de Professores. Pesquisa (Auto)biográfica. Tecituras. Construção da docência de bacharéis.

\begin{abstract}
The purpose of this article is to understand the life trajectories of the bachelor teachers graduated of the Special Program of Graduation of Teacher Education for Professional Education (PEG) in order to investigate the formative processes that led to the construction of teaching. The investigated teachers participated in a doctoral study that sought methodological support in (biographical) research, using biographical-narrative research as a methodology and making use of narrative interviews and field diaries as tools for the production of information. The process of analysis was guided by narrative analysis and produced two "movements": the first involved the reconstruction of life trajectories as
\end{abstract}


narrative texts, composing plots; the second gave rise to the "image" of the "biographical loom", a device that encouraged the interweaving of the plots, making possible the composition of weavings that construct the teaching of the research subjects. It is understood, therefore, that the construction of teaching does not have an exact definition, being built on the paths lived by the subjects, in the ways of writing oneself and in the interweaving of the plots, through the "biographical loom". Plots that carry many stories, many memories and that when intertwined, produced weavings - representations, senses and knowledge - that in this work are not understood as fragmented aspects, but rather as aspects that are articulated in the movement of narrating life, defining the teaching of four PEG graduates.

Keywords: Teacher Training. (Auto) biographical research. Weavings. Construction of the teaching of bachelors.

\section{Resumen}

Este artículo tiene como objetivo comprender las trayectorias de vida de profesores licenciados egresados del Programa Especial de Graduación de Formación de Profesores para la Educación Profesional (PEG) con la finalidad de investigar los procesos formativos que llevaron a la construcción de la docencia. Los profesores investigados participaron en un estudio doctoral que buscó apoyo metodológico en la investigación (auto) biográfica, utilizando como metodología la investigación biográfica-narrativa y haciendo uso de entrevistas narrativas e diario de campo como instrumentos para la producción de las informaciones. El proceso de análisis fue pautado por el análisis narrativo y produjo dos "movimientos": el primer movimiento implicó la reconstrucción de las trayectorias de vida como textos narrativos, componiendo tramas; el segundo movimiento hizo surgir la "imagen" del "tear biográfico", un dispositivo que impulsó el entrelazamiento de tramas, que posibilita la composición de tecituras que construyen la docencia de los sujetos de la investigación. Comprendemos, de esta forma, que la construcción de la docencia no tiene una definición exacta, siendo construida en los recorridos vividos por los sujetos, en los modos de escrituras de sí y en el entrelazamiento de las tramas, por medio del "tear biográfico". Tramas que cargan muchas historias, muchas memorias y que al ser entrelazadas, produjeron tecituras - representaciones, sentidos y saberes. - que, en este trabajo, no se entienden como aspectos fragmentados, sino como aspectos que se articulan en el movimiento de narrar la vida, definiendo la docencia de cuatro profesores licenciados y egresados del PEG.

Palabras-llave: Formação de Professores. Pesquisa (Auto)biográfica. Tecituras. Construção da docência de bacharéis.

\section{INTRODUÇÃO}

"Eu sempre gostei de contar história, porque história é que nem fio: a gente tece e o fio cresce, a gente inventa e tudo o que a gente tenta se transforma em coisa nova (SOUZA, 2007, p. 4). Foi por isso que neste artigo, como resultando de uma pesquisa maior, resolvemos tecer as histórias e entrelaçar as narrativas de quatro professores bacharéis egressos do Programa Especial de Graduação de Formação de Professores para a Educação Profissional (PEG) ${ }^{1}$,

\footnotetext{
${ }^{1}$ O PEG, na modalidade presencial, possibilita uma formação pedagógica para os profissionais portadores de diploma de graduação (bacharéis ou tecnólogos) que atuam, ou pretendem atuar, como professores na Educação Profissional, principalmente Técnica de Nível Médio. Foi criado em 2009 e é uma proposta articulada entre os Centros de Ensino da UFSM - Centro de Educação (CE), Centro de Ciências Rurais (CCR), Colégio Técnico Industrial (CTISM) e Colégio Politécnico da UFSM.
} 
com a proposta de compreender como estes, nos seus movimentos cotidianos, constroem a docência.

Assim como na história de "Tecelina”, narrada por Gláucia de Souza, vamos tecendo a vida e os nossos percursos com pedacinhos de fios de outras histórias - fios que as vezes são macios com cheiro de infância, fios com texturas e sabores que se transformam em lembranças, fios coloridos, resistentes, fios que nos atravessam e revelam quem somos. ( $\mathrm{Re}$ )contar a vida, por meio da narrativa, é como (re)construir os fios que já estavam tecidos: os pontos vão voltando, os nós vão surgindo e os fios vão se modificando, não são mais os mesmos de quando tecemos pela primeira vez. Eles agora, carregam outras marcas, outras memórias, nunca mais serão tecidos da mesma forma, pois, como nos fala Delory-Momberger (2008a, p. 96), “(...) a narrativa de vida nunca é 'de uma vez por todas””. Configura-se como uma "matéria movente, transitória, viva, que se recompõe sempre no momento em que é enunciada".

A capacidade narrativa, em sua forma autobiográfica, consiste, segundo Bolívar, Domingo e Fernández (2001, p. 22, tradução nossa), em dar um sentido global entre passado e presente, estabelecendo uma consistência que, apesar das transformações, mantém uma identidade. Para os autores as narrativas assumem algumas características, a saber: a) "O conhecimento narrativo está baseado em uma epistemologia construtivista e interpretativa" construtivista, porque a linguagem não fica limitada a representar a realidade, mas a constrói, a partir do modo como as pessoas dão sentido ao mundo e as suas vidas; e interpretativa, porque as ações são entendidas como textos a interpretar. b) A narrativa é uma estrutura que possibilita a construção de significados e de identidade pessoal, ou seja, as pessoas pensam, percebem e dão sentido as suas experiências de acordo com estruturas narrativas. c) $\mathrm{O}$ relato narrativo é configurado por uma trama argumentativa ou enredo. d) A temporalidade é uma importante dimensão da experiência vivida, visto que a consciência de nossa vida está estruturada temporalmente. e) "As narrativas individuais e as culturais estão interrelacionadas", visto que cada relato narrativo faz parte de uma determinada comunidade de linguagem (que é social e cultural). Neste sentido, a narrativa é uma estrutura que revela o modo como os humanos constroem sentido para o curso da sua vida e para a construção da sua própria identidade.

A narrativa, na compreensão de Bruner (1988), não expressa somente importantes dimensões da experiência vivida (representações da realidade), mas media a própria experiência e configura a construção social da realidade, à medida que o sujeito atribui sentido a sua vida a partir de uma sequência temporal. A narrativa como forma de construir 
realidade é um modo de organizar as experiências, apropriar-se delas e dos significados particulares e coletivos que elas expressam. Conforme ressalta Bruner (2001, p.11), "É por meio de nossas próprias narrativas que construímos principalmente uma versão de nós mesmos no mundo". Nossas narrativas nos levam a definir quem fomos, quem somos e quem queremos ser.

As palavras de Bruner (1988) nos aproximam das discussões construídas na tese de doutoramento de Dolwitsch $(2018)^{2}$, cujo principal objetivo foi o de compreender as trajetórias de vida de quatro professores bacharéis egressos do PEG a fim de investigar os processos formativos que levaram à construção da docência. Nos conduzindo a pensar em: quais foram os movimentos construtivos empreendidos pelos professores bacharéis ao longo das suas trajetórias que levaram assumir a docência como atividade profissional? Quais são as representações, os sentidos e os significados produzidos pelos professores bacharéis acerca da docência? Quais são os sentidos de ser e construir-se professor na contemporaneidade?

Como forma de problematizarmos esses questionamentos, fazendo um recorte ao que foi proposto na pesquisa de doutorado, e com o objetivo de compreender a construção da docência de quatro professores bacharéis egressos do PEG, buscamos amparo teóricometodológico na pesquisa (auto)biográfica, transitando por meio da metodologia biográficonarrativa e realizando uma análise narrativa para interpretar os dados que foram produzidos. Cabe mencionar que a intenção do processo de análise não foi aspirar um trabalho de generalização, mas valorizar as narrativas particulares de cada participante. "Aqui não buscamos elementos comuns, mas elementos singulares que configuram a história" (BOLÍVAR, 2002, p. 52, tradução nossa).

$\mathrm{Na}$ sessão que segue, delinearemos o percurso metodológico empreendido na investigação, enfatizando os movimentos produzidos para a análise das informações que emergiram da pesquisa. Em uma terceira sessão, procederemos com a problematização das "tecituras" que constroem a docência dos professores bacharéis envolvidos no estudo, delineando, com maior ênfase, as representações, os sentidos e os significados produzidos neste processo. Finalizamos a nossa reflexão com a escrita de algumas considerações finais.

\section{PERCURSOS METODOLÓGICOS}

As histórias de vida, assim como as narrativas, possibilitam que se perceba o sentido de uma vida, justamente porque descrevem, representam e "colocam diante de nós instâncias de

\footnotetext{
${ }^{2}$ Pesquisa realizada com apoio financeiro da Capes.
} 
percursos" (ALARCÃO, 2004, p. 11), que suscitam reflexões, mobilizam pensamentos e motivam ações. As narrativas (as nossas e as dos outros) possuem um valor inspirador, fazem com que possamos ver o mundo e as pessoas a partir de outras perspectivas, movimentam nossas emoções, "mexem conosco e quantas vezes nos transformam". Fazem com que possamos refletir sobre nós mesmos e sobre a configuração pela qual se encontra a sociedade. As narrativas também permitem "escutar sentimentos", rever práticas e perceber "a multidimensionalidade da existência humana" (ALARCÃO, 2004, p. 11).

As narrativas, conforme retoma Alarcão (2004, p. 12), remetem a acontecimentos, descrevem contextos, entrelaçam elementos em um "fio condutor que lhe atribui coerência" e significado. Se as trajetórias de vida individuais já nos remetem a uma pluralidade de sentimentos, ações, percursos, conceptualizações, "novas perspectivas se abrem quando, a partir das histórias de vida, nos lançamos num tipo de análise transversal, meta-narrativa, em busca de configurações, de semelhanças, de singularidades". Ou seja, novas possibilidades podem surgir quando organizamos as narrativas a partir de alguns modos paradigmáticos aceitos dentro da perspectiva narrativa, não com a proposta de produzir generalizações, mas novas conceptualizações, novas tramas narrativas.

Deste modo, a organização metodológica empreendida na pesquisa nos levou à produção de um "tear biográfico". Mas antes de conceituá-lo, é importante mencionarmos como chegamos até ele, quem são os participantes da investigação, quais instrumentos utilizamos para a produção das informações, como organizamos o material coletado (ainda na sua forma bruta) e quais caminhos percorremos no processo de análise para chegar à produção final do relatório de pesquisa.

Cabe destacar que os participantes desta investigação são professores bacharéis egressos do PEG e foram selecionados considerando alguns aspectos, a saber: professores bacharéis que ingressaram no PEG no primeiro semestre de 2016; que atuam/atuaram ${ }^{3}$ na docência no contexto da Educação Profissional e Tecnológica e/ou do Ensino Superior; que atuam/atuaram 1 (um) ano ou mais como docentes. A partir de um levantamento realizado por meio da aplicação de um formulário digital, recebemos o retorno e a disponibilidade de participação no estudo de quatro (04) docentes: Professora P, que tem experiência de 17 anos no Ensino Superior; Professor G, que tem experiência de dois (02) anos na Educação Profissional Técnica de Nível Médio; Professor S, que tem experiência de dois anos na Educação Profissional e Tecnológica, atuando nos Cursos Superiores e Técnicos; e Professor B, com

\footnotetext{
${ }^{3}$ Utilizamos a expressão atuam/atuaram, porque, no contexto da pesquisa, dois participantes ocupavam cargos provisórios (como professores substitutos) no momento da coleta de informações.
} 
experiência de três (03) anos no Ensino Superior e quatro (04) anos na Educação Profissional e Tecnológica, atuando nos Cursos Superiores e Técnicos.

Para a construção das tramas, utilizamos como instrumentos de coleta entrevistas narrativas organizadas a partir de tópicos guia (BAUER; GASKELL, 2011), com tópicos que guiaram a entrevista possibilitando que os participantes trouxessem à tona suas histórias com maior liberdade, a partir de pontos mais específicos da investigação. Além das entrevistas, utilizamos como instrumento metodológico o Diário de Campo, com o intuito de descrever como as entrevistas foram acontecendo e registrar as linguagens não verbais que apareceram no diálogo com os participantes.

Após a realização das entrevistas realizamos a transcrição das informações e a elaboração dos quadros sínteses, com base nas orientações teóricas propostas por Bolívar, Domingo e Fernández (2001). A construção dos quadros não teve a intenção de organizar os dados de acordo com um conjunto específico de categorias comuns, mas auxiliar a organização temporal e temática para a construção das trajetórias individuais, conferindo importância e valorizando as experiências implicadas nas histórias de vida de cada professor participante desta pesquisa. Assim organizamos a análise a partir de dois movimentos.

O primeiro movimento envolveu a reconstrução das trajetórias de vida como textos narrativos, compondo tramas. Essas trajetórias foram reconstruídas com o auxílio do quadro síntese, a partir de alguns "fios biográficos" que conduziram a análise: "percursos formativos" (gênese, lembranças de infância, adolescência e vida adulta, percurso formativo acadêmico); "percursos profissionais" (experiências profissionais e acontecimentos que antecederam a docência); e "percursos na/da docência" (inserção na docência, exigências e desafios, aprendizagens, momentos marcantes, experiências de aula, organização e planejamento das aulas, contribuições do PEG, compreensão sobre o ser professor).

Para compreender a construção da docência de bacharéis egressos do PEG, empreendemos ainda um segundo movimento, fazendo analogia ao tear - artefato ou máquina que permite que os fios se entrelacem para compor o tecido. Mas não um tear qualquer, nesta pesquisa fazemos referência ao "tear biográfico" que são as próprias narrativas de vida repletas de sentidos e significados, que, ao serem rememoradas, produziram movimentos (similares aos do tear) e [re]significações. "Tear biográfico" como um dispositivo que impulsionou, no contexto desta investigação, o entrelaçamento de tramas que carregam 
marcas pessoas, culturais, históricas e sociais, possibilitando a composição de tecituras representações, sentidos e saberes - que constroem a docência de bacharéis egressos do $\mathrm{PEG}^{4}$.

Cabe destacar que o entrelaçamento das tramas não aconteceu por meio de instrumentos de categorização de dados, mas foi realizado pelas pesquisadoras, à medida que fomos construindo as trajetórias individuais. Foi como construir os tecidos por meio do tear, a partir dos "fios biográficos" elaboramos as tramas, a partir das tramas fomos entrelaçando, fomos percebendo como cada participante, nos seus percursos de vida, constrói à docência. Até chegar na composição das tecituras - das representações, dos sentidos e dos saberes que marcam, de certa forma, o modo de ser e constituir-se professor, um processo que, segundo Freire (1987), tem início, mas nunca fim.

Considerando a organização metodológica a partir do enfoque narrativo, é importante ressaltar que a intenção da pesquisa não foi silenciar a voz dos participantes e do investigador, nem mesmo trazer apenas a mera transcrição de dados, mas construir uma trama narrativa que consistiu em dar sentido às informações e representar o significado no contexto em que ocorreu. Buscamos realizar, como menciona Bolívar (2002), uma espécie de "visão binocular", uma "dupla descrição", que envolve pensar: se por um lado, é preciso "um retrato" da realidade interna do informante; por outro é preciso registrar o contexto externo que contribua para dar sentido e significado a realidade vivida.

Assim, o resultado não é um informe objetivo e neutro, nem mesmo uma simples transcrição de dados, consiste em construir uma trama, um enredo, para atribuir sentido às informações narradas, a partir de diferentes contextos, cenários, rupturas; diferentes formas de representar e manifestar a vida que está sendo contada.

\section{O "TEAR BIOGRÁFICO" E AS SUAS TRAMAS: tecituras que constroem a docência de professores bacharéis}

Compreendemos que a construção da docência não tem uma definição exata, sendo construída nos percursos vividos pelos sujeitos, nos modos de escritas de si e no entrelaçar das tramas, por meio do "tear biográfico"; tramas que são únicas, singulares, particulares, identitárias, que carregam histórias, mas que, ao mesmo tempo, são atravessadas por uma pluralidade de contextos, memórias e identidades. Passamos a compreender que a docência, no contexto dessa pesquisa, foi construída por tecituras, pelas representações sobre a profissão pré-concebidas no meio familiar, no processo de escolarização e no percurso

\footnotetext{
${ }^{4}$ É importante destacar que neste artigo daremos maior visibilidade à análise empreendida a partir do segundo movimento.
} 
acadêmico; pelos sentidos que definem o ser professor - consciência de inacabamento, (auto)formação permanente, autoconhecimento, compartilhamento de experiências, movimento, transformações, sonhos, entre outros; e pelos saberes que envolvem a profissão experienciais, culturais, específicos da área do conhecimento, pedagógicos e subjetivos.

Assim, para conceituar o movimento do "tear biográfico", buscamos algumas contribuições teóricas em Delory-Momberger (2008b), a qual entende que toda a biografia é um percurso de formação, visto que ela organiza e estrutura os episódios e as experiências de vida no cenário de uma história. A biografia está relacionada ao campo das representações, às formas como os seres humanos percebem sua existência, como dão forma às suas experiências enquanto "ser social singular". Isso evidencia, segundo Delory-Momberger (2012b, p. 183), o quanto a compreensão narrativa da experiência resulta de uma escrita, ou seja, de uma interpretação do vivido com "sua dinâmica e sua sintaxe, seus motivos e suas figuras", enfim, seus diferentes movimentos.

Deste modo, a nossa biografia está submetida a um processo de reconfiguração que perdura no tempo. "O sentido que damos ao percurso de nossa vida não se cristaliza em formas definitivamente fixas" (DELORY-MOMBERGER, 2008a, p. 58). A todo o momento os acontecimentos passados da nossa história são submetidos a uma "interpretação retrospectiva", que é, por sua vez, "determinada pela antecipação do futuro". Do mesmo modo, as expectativas, os sonhos, as aspirações que projetamos no futuro, são dependentes da rememoração do passado. A biografia constitui-se, assim, segundo a autora, sobre um conjunto de experiências cumulativas que são igualmente "o lugar de experiência" e "de produção da identidade" (DELORY-MOMBERGER, 2008a, p. 58).

É importante mencionar que cada experiência é singular e essa singularidade só pode ser compreendida por meio da lógica biográfica de nossas experiências, que são, por sua vez, "atravessadas" por uma pluralidade de contextos (lugares, pessoas, sentimentos, entre outros). O sujeito se constitui verticalmente na relação com a sua temporalidade, ao mesmo tempo, se constrói horizontalmente na relação com os outros. Assim, “as experiências e as significações da vida nunca atuam na relação única consigo mesmo"; elas extraem seu conteúdo e sua validade das relações subjetivas "que o sujeito encontra em suas primeiras redes de pertencimento" (DELORY-MOMBERGER, 2008a, p. 59).

A construção da narrativa de si possibilita, desse modo, que o sujeito possa vivenciar, no seu processo de formação, aprendizagens experienciais inscritas em suas identidades e subjetividades, explorando distintas experiências, "as quais partem de uma perspectiva fenomenológica da formação e da aprendizagem da profissão" (p. 164). A escrita de si e as 
experiências das trajetórias de vida dos professores, neste trabalho bacharéis que atuam na docência, podem indicar diferentes processos educativos que marcam representações sobre a profissão, saberes da profissão, aspectos culturais do pensamento do professor em formação, "significados sociais e institucionais contidos nas experiências concretas dos sujeitos" e os sentidos que têm o ser professor na sua vida (SOUZA, 2006b, p. 165, grifos meus).

Assim sendo, a partir das compreensões teóricas mencionadas acima, buscamos, por meio das narrativas de vida de quatro professores bacharéis egressos do PEG, investigar os processos formativos que levaram à construção da docência - direcionando o nosso olhar, nesse momento, para as representações, os sentidos e os significados produzidos neste processo.

\subsection{Tecituras... Representações, sentidos e significados construídos sobre a docência}

Trabalhar com narrativas é fazer aflorar sensibilidades, é perceber como os sujeitos, nas suas manifestações no tempo e no espaço, representam as suas experiências, constroem significados e atribuem sentidos à vida. O potencial (auto)formativo das narrativas está relacionado justamente com as singularidades que cada sujeito expressa ao rememorar sua vida, revelando escolhas e particularidades de cada contexto. No que se refere a esta pesquisa, o que potencializou o trabalho com a abordagem biográfica não foi a quantidade das lembranças rememoradas, mas o processo de formação que cada um estabeleceu no movimento de construir-se professor.

As referências contidas nas narrativas de vida dos professores da pesquisa indicam que a opção por assumir a docência como atividade profisssional vem marcada por representações sobre a profissão - pela influência de professores e pessoas significativas, pela busca de estabilidade financeira, pela afinidade com a área de formação, pela participação em atividades extracurriculares, enfim, pelas experiências e aprendizagens singulares percorridas em contextos plurais. Desta forma, constituir-se professor não foi algo planejado por nenhum dos participantes da pesquisa, nenhum deles teve, inicialmente, a intenção (ou o sonho) de assumir a docência como profissão. Tornar-se professor foi, para eles, "uma aprendizagem experiencial e formativa inscrita na visão positiva que os sujeitos têm sobre si (...) e na superação e acolhimento de alguns modelos formativos" vividos nos seus percursos de escolarização (SOUZA, 2006b, p. 144). Conforme marcam algumas narrativas: 
O meu pai e a minha mãe sempre foram estudiosos, professores, mas não por isso que a gente pensava em ser professor, porque eu não pensava, que eu me lembre nunca brinquei de professora, sempre ajudei o meu irmão mais novo nos estudos, mas nunca com aquela questão de criança ser professor, não que eu me lembre (PROFESSORA P, p. 1, grifos nossos).

Ao lembrar dos pais, a professora $\mathrm{P}$ revela que estes sempre foram estudiosos, mas deixa claro que a sua escolha profissional não surgiu desta referência familiar. $O$ desejo pela docência surge em um processo de (auto)reflexão, a partir de uma experiência que teve na graduação - um acontecimento que marcou a sua trajetória acadêmica, fazendo surgir uma outra possibilidade que não estava nas suas aspirações iniciais (de ser astronauta, piloto de aeronaves, médica veterinária, policial, advogada, arquiteta).

Em vista disso, a rememoração do passado não implica apenas relembrar os fatos que perduram na memória e que ainda fazem o coração bater mais forte, mas um reencontro com eles, no sentido de reconhecer quais aprendizagens e experiências foram formadoras e nos constituíram enquanto sujeitos individuais e sociais. Em suas "representações biográficas", segundo Delory-Momberger (2012a, p. 189), o sujeito "dispõe e experimenta o processo de formação mediante o qual ele produz a si próprio".

(...) na faculdade teve vários professores que buscaram a criatividade que eu
adorei. E teve um que quando tu se dedicava ao máximo não era o ideal, ele
vinha com defeito, e a gente percebia que não era significativo. E ai eu
comecei a tentar melhorar ainda mais (risos), e quanto mais a gente fazia
parece que ele ficava mais irritado. E ai eu perguntava, por que tu não quer
explicar? E aí ele dizia: eu não vou explicar pra vocês, porque vocês vão ser
os meus futuros concorrentes. E aquilo me chocou muito né, acho que foi no
terceiro semestre, não me lembro agora cronologicamente, e justamente por
me chocar bastante, fez eu refletir. Então foi a partir daí que eu comecei a
minha autoconstrução como professora. Foi a partir disso que eu disse:
não, eu quero ser uma professora para não ser igual a ele. Então eu
comecei a pensar em ser professora nesse momento dessa reflexão, até então
eu não tinha pensado em ser professora (PROFESSORA P, p. 5, grifos
nossos).

Entender o significado exercido pelas experiências escolares no cotidiano dos professores, incluindo as vividas no percurso acadêmico, pode tornar-se, conforme Souza (2006b, p. 140), um dispositivo importante para compreender as fertilidades e as relações que esses espaçostempo têm exercido sobre os sujeitos; "seja do ponto de vista histórico, didático-pedagógico, das áreas de conhecimento", enfim, das lembranças dos processos formativos que integram às histórias dos sujeitos. Em relação a isso, Bolívar, Domingo e Fernández (2001) mencionam que o relato de formação de cada um, tem condicionado o próprio processo de tornar-se 
professor, constituindo-se em um meio de transformação (e não de reprodução) nas formas de conduzir o trabalho docente.

A escolha pela docência na trajetória do professor $S$ também foi marcada por representações construídas nos "tempos" de graduação, especialmente pela influência de um professor da área de finanças que, apesar de ser duro, se preocupava com a aprendizagem significativa, contextualizada e aplicada à realidade dos alunos. Alguém que trouxe inspiração - pelo modo ser, por ter autoridade e não ser autoritário, por saber conduzir e mediar a turma, por acolher os questionamentos e os anseios e, principalmente, por ter uma boa aproximação e um bom diálogo com os alunos.

Na UFSM eu conheci um professor e esse professor é o que me inspirou a ser docente na área da administração financeira, não só pelo jeito dele, mas talvez pelo modo como ele transmitia as coisas por trás dos conceitos, o contexto né, as experiências que ele tinha. Ele era duro, só que ao mesmo tempo ele tinha uma boa aproximação com os alunos. Era uma maneira de ter a disciplina, mas com uma aproximação bem legal com os alunos. E foi esse cara que me mostrou que na disciplina o que vale não é a nota, mas o teu aprendizado (PROFESSOR S, p. 2, grifos nossos).

Tais aprendizagens são experiências construídas ao longo da vida, nos tempos e espaços de formação, que deixam marcas e imprimem reflexões sobre o que se viveu. "Tempos marcados na memória e nas histórias sobre o sentido da vida e da profissão. Espaços que são entrecruzados nas itinerâncias e nos desafios da aprendizagem profissional" (SOUZA, 2006b, p. 15). Uma formação que acontece nos percursos de vida, pelas experiências, pelos saberes e por práticas que possibilitam a (re)construção dessas aprendizagens.

A trajetória formativa do professor B foi impulsionada pelas influências familiares, principalmente, pelas do pai, que, por ser bancário, compreendia que esta carreira poderia ser promissória para o filho. Para Dominicé (2010b, p. 87), “(...) os pais são objeto de memórias muito vivas" no exercício de rememoração. Com eles é possível estabelecer, segundo o autor, relações particulares que, algumas vezes, orientam os percursos escolares e profissionais e causam certos desconfortos. “(...) realizar a formação profissional exigida pelos pais antes de iniciar a carreira que se escolheu constituem alguns exemplos de confronto" que revelam "um movimento de emancipação por meio do qual o adulto dá progressivamente forma à sua existência" (DOMINICÉ, 2010b, p. 87). Assim, o professor B encontrou, a partir de suas experiências, elementos significativos que o possibilitaram exercer a sua vontade e iniciar um processo de escolha profissional.

A administração assim como um todo não tinha me despertado um grande interesse, mesmo até o final do curso. Dai quando eu entrei nessa área de finanças eu comecei a gostar mais, eu percebi que eu tinha mais habilidade para aquilo, 
era fácil pra mim, pras outras pessoas parecia mais dificil (...). Mas apesar de eu ter começado a gostar, profissionalmente falando, eu não tinha, nunca tive até aquele momento, intenção de me tornar professor. Isso jamais tinha passado pela minha cabeça, nunca passou, mas dai um dia eu tava andando na rua e encontrei um cara que tinha sido meu professor na administração e ele falou: ó, tem processo seletivo pra mestrado, tu não quer fazer o processo seletivo? E foi a partir do ingresso no mestrado que o interesse começou a surgir (PROFESSOR B, p. 2-3, grifos nossos).

Foi em uma das suas experiências dentro do curso - a partir de influências de pessoas significativas do meio acadêmico e pela afinidade com a área de formação - que ele começou a refletir que poderia ser um bom professor, conforme expressa a sua narrativa:

(...) eu lembro que teve uma aula de estatística em função das pesquisas, era uma coisa instrumental pra ti usar nas pesquisas e eu tinha uma certa facilidade, eu entendia bem, mas os meus colegas não estavam entendendo nada, nada, nada. Dai um dia a gente se reuniu e eu comecei a explicar, fui pro quadro, destrinchei uns cálculos, expliquei as questões teóricas pra eles, e dai naquela brincadeira eles começaram, os meus colegas começaram a achar que eu seria um bom professor. E daí (risos) foi, eu comecei a pensar: tá bom então, já que o pessoal acha que eu seria um bom professor, então quem sabe eu arrumo um trabalho num curso de administração de noite só pra me manter fazendo alguma coisa. (PROFESSOR B, p. 3, grifos nossos).

Nesse sentido, podemos compreender que a escolha de uma profissão não é somente pessoal, ela pode ser transversal aos aspectos sociais que integram o nosso cotidiano: as relações construídas na família, com os amigos, no ambiente acadêmico; os vínculos estabelecidos com os professores, as decepções e as conquistas que marcam nossas trajetórias e quantas vezes nos transformam.

Nas palavras de Dominicé (2010b), “(...) aquilo em que cada um se torna é atravessado pela presença de todos aqueles que se recorda. Na narrativa biográfica, todos os que são citados fazem parte do processo de formação" (p. 87). Assim, esse processo está implicado no de socialização, em que “(...) os contextos familiares, escolares e profissionais constituem lugares de regulação de processos específicos que se enredam uns nos outros, dando uma forma original a cada história de vida" (p. 94).

Em outras situações, como revela a narrativa de vida do professor G, o interesse pela docência surge a partir de algumas experiências com o ensinar, por meio de atividades extracurriculares desenvolvidas no seu percurso de graduação. Neste contato inicial com a docência, mesmo no processo de formação inicial, a vida profissional do professor apresentase, segundo Huberman (2000), como um misto de descoberta e complexidade, em que o 
graduando tem a possibilidade de observar a realidade da profissão, buscar suas próprias estratégias e definir algumas direções para concretizar suas escolhas.

Como eu participava do PET (...), e o PET tem a parte de ensino além da pesquisa e da extensão, foi onde que eu comecei com a parte da docência. Foi proposto um minicurso para explicar a parte teórica e a parte prática de um software, eram três semanas. E ai eu tive que preparar todo o projeto, preparar aula, preparar material, preparar apostila. Foi a primeira vez, que eu entrei numa sala de aula com um monte de alunos para explicar um conteúdo. (...).. Então naquele dia eu percebi, é legal, não é ruim, eu tinha achado interessante dar aula, mas foi bem puxado, fazer o minicurso inteiro sozinho, correr atrás de certificados, correr atrás de projeto, de coffee break, de tudo. Fazer toda a logística é mais trabalhoso do que dar aula (PROFESSOR G, p. 23, grifos nossos).

Além disso, a sua inserção na indústria, a partir do processo de Estágio Supervisionado dentro do Curso de Engenharia Elétrica, o fez perceber que o "mundo acadêmico" poderia aproximá-lo, de alguma forma, de algo do qual ele gostava bastante e que também tem vínculo com a docência: a pesquisa.

(...) o estágio meio que me abriu assim a ideia: não é bem isso que eu quero, vou voltar pro meio acadêmico, voltei pro mestrado, que eu sempre gostei da pesquisa. Por mais que eu não consegui fazer, implementar muita coisa na pesquisa, eu gosto de pesquisar uma área que seja, digamos, prática, que seja aplicada, não uma área basicamente teórica. Então eu tinha um projeto legal de pesquisa e eu acabei voltando pro mestrado. Eu comecei o mestrado (...) e eu não consegui bolsa e nem tinha possibilidade de receber dentro de um ano. Ai, nesse meio tempo, apareceu a oportunidade no CTISM, foi quando que eu disse: vou arriscar, vamos ver o que vai acontecer. Já tinha experiência no PET, já tinha ficado em uma sala cheia de alunos, já tinha apresentado trabalho em inglês fora do Brasil, vamos tentar. Como eu sempre digo a gente precisa tentar e ver se é realmente aquilo que a gente quer, que a gente gosta. Ai foi quando apareceu a oportunidade de entrar como substituto e eu comecei (PROFESSOR G, p. 23-24, grifos nossos).

Com a inserção no mestrado, a expectativa de receber bolsa não se concretizou. Dessa forma, a opção pela docência apareceu ainda, na trajetória de vida do professor $G$, impulsionada pela busca de estabilidade financeira, mesmo que uma busca provisória. Quando analisamos as narrativas desse professor, percebemos o quanto as suas escolhas estão entrelaçadas pelos desafios e pelas oportunidades que surgiram nos seus percursos formativos e que compõem, hoje, a sua trajetória profissional. Isso nos remete ao que escreve DeloryMomberger (2008a, p. 58), que "cada momento biográfico, apesar de possuir experiência própria, está ligado a um passado e a um futuro", dos quais o sujeito que escreve a sua vida retira sua forma e sua significação. 
Assim, a escolha pela docência nas trajetórias dos professores bacharéis participantes da pesquisa perpassa por uma construção social, que adquire sentido e significado pelas representações construídas no decorrer dos percursos singulares e plurais vivenciados pelos sujeitos. Essa perspectiva de construção social é problematizada por Tardif, Lessard e Gauthier (2001, p. 11), que compreendem que as profissões não são realidades naturais, mas estão inscritas em dimensões sócio-históricas produzidas pela ação dos sujeitos como atores sociais, que agem em contextos já condicionantes e estabelecem suas próprias interpretações, a partir do que são, do que viveram e das experiências que construíram ao longo da vida.

\subsubsection{Ser e construir-se professor...}

A narrativa (auto)biográfica institui "um sistema de interpretação e de construção" permitindo que os acontecimentos da vida sejam significados a partir de elementos organizados no interior de um todo. Segundo Delory-Momberger (2008a, p. 58), do mesmo modo que, para o hermeneuta, as partes do texto (palavras, frases, parágrafos, etc) só adquirem sentido na relação com o todo e vice-versa, para o autor de sua biografia, o sentido se constrói na integração "da figura total da vida e de suas partes". As experiências encontram seu lugar e adquirem sentido no contexto construído pela qual o homem representa, para si mesmo e para os outros, o curso de sua vida. Assim, todo o relato de vida é, na compreensão de Bolívar (2016), uma busca de sentido e uma justificação razoável que confirme ou questione a trajetória enunciada.

Diante disso, cabe algumas problematizações: o que é ser professor? Qual o sentido de ser e construir-se professor nos dias atuais? O que as narrativas de vida dos participantes da pesquisa - professores bacharéis - nos dizem, representam, significam, inscrevem?

Na compreensão de Gadotti (2003, p. 15), ser professor na contemporaneidade "não é nem mais difícil nem mais fácil do que era há algumas décadas atrás"; é um processo diferente, permanente e inacabado, principalmente em função das transformações vividas pela sociedade e "da velocidade com que a informação se desloca, envelhece e morre". As exigências definidas pela sociedade do conhecimento vão além da atualização e assimilação de conteúdos, normas e saberes. Os desafios, agora, são maiores, seja para a educação, para a escola ou para os professores: "ensinar a pensar; saber comunicar-se; saber pesquisar; ter raciocínio lógico; fazer sínteses e elaborações teóricas; (...) ser independente e autônomo; saber articular o conhecimento com a prática" (p. 16); saber compartilhar e compreender o outro na sua fala, no seu contexto e na sua história. Assim, o professor assume, atualmente, um importante papel. 
Para o professor $\mathrm{G}$, ser professor é transformar o pensamento de alguém, apontar alguns caminhos e nortear algumas aprendizagens; é "fazer as pessoas refletirem, (...) pensarem" e com isso criar possibilidades de construção de conhecimentos. É compreender que:

\begin{abstract}
(...) ser professor é tu explicar não só a parte técnica, mas conseguir mostrar para as pessoas que elas podem ser mais, que elas podem buscar o que elas quiserem, que elas têm capacidade. (...) então eu acho que não é só simplesmente tu chegar lá e explicar um conteúdo. (...) é entender que muitos se inspiram no teu trabalho, se inspiram nas tuas ideias, e tu tem o poder de influenciar e transformar pensamentos, mostrar que a vida não é tão simples, que a vida tem muitas dificuldades. (...). Não pensar que é só eu, que o importante é eu e mais nada, mas pensar nos outros, pensar que a gente vive numa sociedade, que tem gente com dificuldade, que tem gente passando fome, que é importante ajudar os outros, fazer o melhor pelos outros. Então ser professor é fazer com que as pessoas pensem, reflitam, tenham capacidade técnica e sejam mais humanas, não só repetidoras de conhecimentos, mas tenham pensamento crítico (PROFESSOR G, p. 37-38, grifos nossos).
\end{abstract}

Essas narrativas revelam o compromisso social, ético e humano de um professor que não está preocupado apenas em ensinar conteúdos técnicos, mas sim em ser alguém que inspira aos seus alunos. Compreende que a sua atuação junto aos jovens e adultos da Educação Profissional pode organizar-se em um espaço democrático, dialógico e, sobretudo, em um espaço para falar e refletir sobre a vida. Entendimentos que nos levam ao que escreve Freire (1997, p. 59), quando menciona que um educador democrático vive, no seu cotidiano escolar, a difícil, mas possível experiência de falar aos educandos e com eles. Ele "sabe que o diálogo não apenas em torno dos conteúdos a serem ensinados mas sobre a vida mesma, se verdadeiro, não somente é válido do ponto de vista do ato de ensinar, mas formador", para que os alunos se tornem sujeitos críticos e responsáveis, capazes de intervir na sociedade para torná-la mais ética e justa.

Além disso, é preciso pensar em uma formação interativa e dialógica que valorize a necessidade de uma atualização permanente em função das transformações produzidas constantemente pela sociedade. Assim, o maior desafio para as instituições que estão envolvidas com o processo formativo dos professores é promover não só a formação profissional, mas comprometer-se com uma formação cultural e contextual, promotora "da mudança e da inovação" (IMBERNÓN, 2011, p. 64).

(...) eu como professor aprendi muita coisa com o PEG, com a escola mesmo, com as ideias dos outros professores (...). Eu acho que o trabalho do professor não para um dia, não adianta, tu precisa estar sempre te atualizando. Talvez para a nossa geração seja mais fácil, eu tive um contato bem mais cedo com a tecnologia do que, por exemplo, os meus pais ou professores mais antigos. Então tu tem um acesso maior à informação, tu 
tem essa facilidade. E eu acho que com o decorrer do tempo muita coisa vira ainda, a gente não pode parar, simplesmente achar: a eu vou explicar aqui com desenho no quadro ao invés de utilizar um celular; eu vou simplesmente mostrar e passar no quadro ao invés de levar o pessoal no laboratório, onde cada um pode montar o seu e fazer na prática (PROFESSOR G, p. 38, grifos nossos).

A docência, como aprendizagem da relação, está conectada, na compreensão de Gadotti (2003), a um "profissional do sentido", que sonha, elabora projetos, busca autonomia na formação e não tem medo de emocionar e emocionar-se, “(...) numa era em que aprender é conviver com a incerteza" (p.22). Por esse motivo, não tem mais sentido a existência de um profissional que se limita a reproduzir conhecimento e cultura. Vivemos novos tempos, "o professor hoje precisa ser um profissional capaz de criar conhecimentos" (p.22), capaz de arriscar-se porque acredita na mudança, e "fazer diferente" pode ser uma possibilidade para viver e conviver no mundo das incertezas.

Para Viviane Mosé (2013), a incerteza pode ter sido um dos grandes ganhos da sociedade contemporânea. "Se antes o parâmetro era a verdade, hoje a regra é saber lidar com a instabilidade. Se nos orgulhávamos de nossos princípios inquebráveis, hoje nos vemos cada vez mais enredados" (p. 53) em múltiplas perspectivas que se transformam o tempo todo, a partir dos diferentes olhares, concepções e valores. Vivemos mudanças tecnológicas; o mundo vive um processo de instabilidade econômica, social, política e ambiental e o modelo educacional vigente nas instituições de ensino públicas e privadas, "fundado em verdades, em saberes acumulados, sem espaço para a invenção e para a dúvida, não foi preparado para isso" (p. 53). Assim, existem inúmeros desafios.

Talvez o maior deles, conforme menciona Gadotti (2003, p. 26), esteja na mudança de mentalidade, não só dos professores, mas da sociedade, e, principalmente, dos sistemas de ensino. A noção de "qualidade" precisa envolver muito mais a capacidade do docente de se relacionar com os alunos, de liderança, de atuação comunitária, do que a capacidade de "passar conteúdos". Uma nova cultura profissional, na compreensão do autor, implica "uma redefinição dos sistemas de ensino e das instituições escolares", uma mudança que precisa partir dos próprios professores e das novas concepções sobre o seu papel. Problematizações que vão ao encontro das narrativas da professora $P$.

o sistema de ensino, a meu ver, não está correto. Eu reavalio o ensino básico com meus filhos, quando eu era estudante eu até não reavaliava, mas hoje eu vejo que não pode ser assim, tem que transformar logo. Em relação ao conteudismo, por exemplo, o que nós temos de conteúdo hoje, na verdade, são reproduções feitas de vários tempos passados. Eu vejo isso bem claro, eu tenho uma filha de vinte e dois, um guri de dezessete e agora uma filha de 
cinco anos, dentro do acompanhamento da educação deles o que mudou? São gerações totalmente diferentes, dos cinco anos para os vinte e dois, e diferente da minha época, e praticamente o conteúdo é o mesmo. Mas nossas inovações tecnológicas são totalmente diferentes. Como é que um sistema de educação ainda continua com aqueles polígrafos que mudam só um pouco a parte do português (a ortografia) e o design? E o conteúdo? Será que é esse o conteúdo que os jovens necessitam saber para interagir no mundo hoje? Eu vejo que não (...) a meu ver teria que ter toda uma reavaliação (...), percebendo o que realmente pode ser modificado. (PROFESSORA P, p. 26, grifos nossos).

Talvez o nosso papel seja entender que o conhecimento está sujeito a mudanças, que os saberes são plurais e provisórios, que não cabe mais a proposta de verdades absolutas e que o conhecimento precisa ser construído de forma compartilhada, a partir das experiências dos alunos e dos professores. O espaço formativo não pode ficar restrito à passividade, ao ensino de conteúdos vazios e sem contextualização, mas precisa ser um "espaço vivo" de ações, interações e desafios, que possibilitem aos alunos refletirem sobre quem são, qual sociedade pertencem e como podem intervir no processo social para pensar em uma transformação. Por isso, conforme expressa a narrativa da professora $\mathrm{P}$, é preciso "promover outro tipo de conhecimento". É preciso construir um espaço e um diálogo com base na emancipação humana, do modo como propõe Paulo Freire, onde as pessoas, respeitando a si mesmo, o outro e a natureza, possam ter liberdade para dizer e construir a sua palavra.

E é a partir dessa "busca de transformação" da escola, do sistema de ensino, enfim, da educação que "eu reavalio o meu papel como professor do Ensino Superior" (PROFESSORA P, p. 23).

O professor precisa mostrar que tudo foi segmentado dentro da formação, que o conhecimento foi segmentado, mas agora é o momento de fazer elos. O professor precisa fazer um movimento para que eles comecem a entender que tudo isso faz parte de um todo e esse todo é onde nós vivemos, que é o mundo, e o mundo não só a terra, pra mim é muito mais que isso. É preciso compreender que o nosso papel nesse todo, mesmo que seja insignificante, é significativo pra rodar as coisas. A imagem pra mim traduzir isso é uma engrenagem e nós somos uma areia, pode não ser nada, pode passar a roda por cima, mas também ela pode emperrar aquela engrenagem. Então eu não quero ser essa areia de emperrar, eu quero ser a areia que vai fazer escorregar aquela roda. E eu acho que é isso que a gente precisa fazer como professor, fazer que o aluno saiba rodar aquela roda pra vida dele e tentar despertar aquele ser humano da melhor forma possível. (PROFESSOR P, p. 23-24, grifos nossos).

As "histórias" que narramos sobre nós mesmos e que nos "levam", algumas vezes, a outras histórias (pessoas, lugares, cenários, imagens), "têm por efeito", segundo DeloryMomberger (2012b, p. 183-184), “articular nosso espaço-tempo individual ao espaço tempo- 
social”. Haja vista que a sequência narrativa que construímos, em suas formas e conteúdos, deixa transparecer um conhecimento dos contextos, das instituições, das práticas, daquilo que somos e acreditamos, pois coloca em ação "uma racionalidade social na qual estamos envolvidos". Assim, o "espaço do biográfico" faz aparecer a dimensão socializadora da atividade biográfica, "o papel que ela exerce na maneira que os indivíduos se compreendem a si mesmos e se estruturam numa relação de (co)elaboração de si e do mundo social”.

Neste momento, cabe trazer o que escreve Gadotti (2003, p. 35), sobre os professores terem um papel fundamental e decisivo nas mãos - a "construção de um novo paradigma civilizatório". Isso só será possível se compreenderem de outra forma a sua função na sociedade e "educarem para a humanidade", para o pensamento crítico, para a emancipação, já que, o propósito da educação, nas palavras de Imbernón (2011, p. 28), “é ajudar a tornar as pessoas mais livres, menos dependentes do poder econômico, político e social”.

Diante dos desafios que já percorremos e dos diversos que ainda precisamos percorrer, qual é o sentido de ser professor nos dias atuais? O que nos move como professor e como ser humano? Para a professora $\mathrm{P}$, ser professor não envolve apenas o ato de ensinar, significa participar do processo de transformação, e nós diríamos até de humanização, junto com os alunos. Mas ela reconhece que “(...) não são todos os professores que pensam assim. E aí vem aquela pergunta: o que é ser professor?” Ser professor é “(...) perceber o olhar daquele aluno, que pode ser tão melhor, ou aprofundado, ou criativo que o próprio olhar do professor que estava ensinado aquilo como concepção" (PROFESSORA P, p. 28).

(...) eu estou falando isso, porque eu acho importante entender que a educação não está certa, tá faltando esse momento, entendeu, falta um momento deles. Eu acredito muito assim, quando eu vejo os grandes mestres, eu digo: essa era a educação ideal né, de tu ter cinco alunos e fazer a caminhada junto com eles, porque dai tu consegue dar atenção. Nessa massificação da educação a gente não consegue dar atenção suficiente pra todos, a gente até tenta, mas não consegue envolver o nivel pessoal, o nivel interpessoal, as angústias, as necessidades, poder ajudar nessa formação. Então pra mim a gente tá fazendo um papel de professor, mas antigamente a gente era educador. E eu sinto falta de ser isso, eu quero ser um educador, não quero ser um professor, eu não tô ali pelo dinheiro, eu tô ali porque eu gosto. (PROFESSORA P, p. 14, grifos nossos).

Numa época de incertezas, mudanças, transições, o professor precisa ser aquele que constrói sentido junto com os seus alunos - aquele que faz “(...) a caminhada junto com eles”, porque sente prazer em fazer isso. Alguém que entende o processo de ensino e aprendizagem como projeto de vida, como possibilidade para "reascender o sonho" e lutar pela esperança, em um processo verdadeiramente educativo. "O importante é aprender a pensar, a pensar a 
realidade" e não apenas "pensamentos já pensados". A partir disso, pronunciar-se, com a proposta de intervir na sociedade para transformá-la e torná-la mais humana (GADOTTI, 2003, p. 53). Talvez esse seja o modo de "acordar" o educador que vive dentro de nós. "E aí aprenderemos que educadores não se extinguiram como tropeiros e caixeiros" (ALVES, 2000, p. 37). Educadores continuam a existir.

Problematizações que nos levam às narrativas da professora $\mathrm{P}$, quando ela menciona que para participar deste processo de transformação, “(...) o professor precisa de mais tempo de capacitação, ele precisa se entender como pessoa, para poder ter essa comunicação e mostrar o seu papel de transformação" (p. 24). Os professores, enquanto sujeitos que participam da formação crítica e social dos seus alunos, precisam assumir o seu papel da melhor forma possível e “(...) buscar se autoconhecer para ajudar o outro se autoconhecer” (p. 24). Para isso, “(...) a gente precisa se fortalecer de conhecimentos para que o outro também possa conhecer, tentando melhorar sempre. Não tem fim. Eu não me vejo dizendo que estou pronta, ninguém vai estar, é uma busca" (p. 24).

A formação permanente do professor precisa contemplar a ação, a pesquisa, a descoberta, a fundamentação e a construção teórica, mas, acima de tudo, permitir que o professor reflita criticamente sobre a sua prática (FREIRE, 1996). O caminho para esse processo de reflexão, segundo Imbernón (2011), exige uma proposta crítica de intervenção educativa, uma análise da prática a partir de "pressupostos ideológicos e comportamentais" (p. 51), que definem quem eu sou como ser humano e como professor - "Eu não acho que tudo o que eu faço tá certo, mas pelo menos eu tento não errar né, tento dar o máximo" (PROFESSORA P, p. 11). O importante não é acertar sempre, mas reconhecer que posso fazer melhor e buscar outras possibilidades.

Assim, é importante perceber que a construção docente da professora $\mathrm{P}$, no contexto universitário, pode ter sido entrelaçada pelas representações e pelos sentidos atribuídos a si mesma em seu percurso de vida, de formação e profissional. Desde a infância, quando a professora narra sobre a importância de considerar o seu tempo para aprender; quando reflete sobre o valor das amizades; quando valoriza a sua independência como mulher e a construção da sua própria identidade; quando revela que o sentido de ser professor “(...) é uma busca”, já que envolve compreender os alunos como seres humanos, “(...) ter essa empatia de perceber o que que o outro precisa" (p. 15) e, ainda, respeitar cada um no seu tempo, no seu espaço e nas suas circunstâncias de vida. "A memória existe para que as pessoas não esqueçam que possuem uma história, um compromisso e uma responsabilidade de usarem a imaginação e a capacidade de criação, a fim de pensar novas formas de educar” (ANTUNES, 2001, p. 48). 
Para o professor S, ser professor é construir espaços de compartilhamento, é estar aberto para o diálogo, é incentivar o pensamento crítico, é pensar em uma formação mais humana, em que o aluno possa refletir sobre os seus valores, sobre o seu caráter, sobre a sua postura perante a sociedade, além da construção de conhecimentos científicos. No seu entender, " $O$ professor não é imparcial, de alguma forma ele vai transmitir alguma coisa, seja ela positiva ou não. Independente da esfera de ensino, na parte técnica ou no superior, o professor é um formador de opiniões, um formador de caráter" (p.8).

Palavras que nos conduzem ao que escreve Freire (1996), ao declarar que ser professor é assumir uma posição perante a sociedade, já que a educação é uma forma de intervir no mundo. "Não posso ser professor se não percebo (...) que, por não poder ser neutra, minha prática exige de mim uma definição. Uma tomada de posição" (p. 102). Exige de nós algumas escolhas e não escolher também revela nossa decisão. "Sou professor a favor da luta constante contra qualquer forma de discriminação" (p. 102-103). Sou professor porque acredito na esperança e na boniteza de minha própria prática, sem cair na arrogância. Sou professor porque defino minhas ações e elas revelam quem eu sou. Assim, tão importante quanto o ensino dos conhecimentos científicos, "é o meu testemunho ético ao ensiná-los" e "a coerência entre o que digo, o que escrevo e o que faço" (p. 103).

Problematizações que se articulam novamente com as narrativas do professor $\mathrm{S}$, quando diz:

Eu vou contar uma coisa, essa semana eu recebi um e-mail de um aluno que está no mestrado, foi meu aluno semestre passado. Dai ele descobriu que eu iria sair do Instituto Federal né e ali ele falou: professor as suas ações ajudaram a definir o meu caráter hoje e fizeram eu perceber que um dia também posso ser docente. Então isso, eu não chorei porque as vezes a gente não gosta muito de chorar, mas isso mostra que o professor, com as suas ações, pode influenciar o aluno na sua formação como cidadão, como docente, como uma pessoa crítica; pode influenciar na construção do caráter, pode auxiliar o aluno a refletir sobre suas ações $e$ a tomar decisões para a vida (PROFESSOR S, p. 8, grifos nossos).

Neste sentido, o professor possui, segundo Imbernón (2011), conhecimentos objetivos e subjetivos, ou seja, tão importante quanto possuir conhecimentos e saber compartilhá-los com os alunos, são as atitudes assumidas nesse contexto. "Um professor ou professora podem ter o mesmo conhecimento, sem que consigam compartilhar as decisões, a comunicação, a dinâmica do grupo etc. por um problema de atitudes" (IMBERNÓN, 2011, p. 16). É importante ter em mente que as minhas ações também produzem saberes e influenciam pensamentos. Assim, é fundamental a construção de um espaço formativo em que a discussão acerca das atitudes - do modo de intervir, de se relacionar, de se comunicar, de sensibilizar-se 
com o outro e com as suas necessidades - seja tão importante quanto problematizar sobre os conteúdos, pois ser professor é estar disposto à mudança, é participar de um processo permanente de emancipação humana, em que a educação seja compreendida como prática de liberdade (FREIRE, 1999).

(...) as vezes a gente acha que a gente não tocou, não marcou aquele aluno, $e$ dai vem aquele retorno que realmente o nosso trabalho é significativo. Então é importante também esse retorno, pois, muitas vezes, a gente acha que a gente tá se dedicando, pensando em algo novo e aquilo não vai ter uma repercussão de forma efetiva ou da forma como nós estávamos pensando. E na verdade tem, só que as vezes o aluno não compartilha naquele momento, como é importante esse retorno depois, até para a nossa autoestima, a gente sente que o nosso trabalho tá dando certo, que estamos no caminho certo. E que bom que a gente também deixou essa liberdade de ele transmitir isso, as vezes o professor marca, mas não te dá a liberdade de tu falar isso (PROFESSOR S, p. 15, grifos nossos).

A docência envolve ainda um caráter interativo, pois, conforme menciona Tardif (2002), ensinar implica interagir com os alunos, não só no sentido de envolver a aprendizagem de conhecimentos científicos, mas também, de valores, atitudes, formas de ser e estar no mundo. "Reconhecer a interatividade como um traço característico da docência é considerar que o processo formativo se desenvolve num contexto grupal, em que pessoas com histórias de vidas distintas se implicam mutuamente" (SOARES; CUNHA, 2010, p. 27). Isso exige que o professor compreenda o processo de ensino e de aprendizagem a partir de elementos relacionais que emergem como possibilidade para analisar conhecimentos, valores e atitudes.

O professor S considerou importante e formativo o processo de falar a partir da infância de "percorrer" a sua trajetória de vida para entender como foi a sua construção docente, pois entende que desde o primeiro contato com a escola, “(...) nem que seja para comer o macarrão com o feijão no intervalo" (p. 14), já vamos compondo algumas representações, “(...) vamos vendo o ambiente, observando a maneira como a professora dá aula, percebendo os problemas e as relações" (p. 14). Nesse momento já vai acontecendo "a transmissão do caráter, dos valores" e tudo isso vai contribuindo para a nossa formação enquanto aluno e enquanto pessoa; e “(...) faz com que a gente reflita, depois, que a docência também é uma experiência maravilhosa. Então esse processo realmente vem de muito tempo" (p. 14).

Essas narrativas encontram sintonia com as discussões propostas por Bolzan e Isaia (2010), quando mencionam que aprender a ser professor não é um processo generalizado, e sim algo que acontece no contexto de cada professor, a partir das trajetórias formativas que podem indicar caminhos para a docência, levando em conta as dimensões pessoais e profissionais. Desta forma, "Os diferentes movimentos construtivos dos professores 
dependem da interação e dos processos formativos que eles colocam em andamento e da própria aprendizagem da docência que os acompanha ao longo de toda a carreira" (p. 19, grifos das autoras). Esses movimentos podem ainda gerar novos percursos possibilitando outros desafios.

O sentido de ser professor é construído também pelas relações e pelos vínculos estabelecidos dentro da instituição de ensino, é o que revela a narrativa do professor B, quando diz que "no início foi uma época ruim".

Lá no IF quando eu cheguei não foi nada fácil, porque tinha um grupo de professores que estavam lá há muito tempo e eles participaram da criação de um curso chamado Tecnologia em Gestão Pública e eles estavam com aquilo bem consolidado, cada professor tinha as suas disciplinas. E eu naquele semestre eu não dei aula em nenhum curso superior e aquilo me incomodou muito, e eu reclamei pros meus colegas que eles estavam sendo injustos né, porque todo mundo tinha que dar aula em todos os cursos. (...) Então foi tenso assim e eu não tava gostando nem um pouco do trabalho naquele semestre, eu pensei até em sair e fazer outros concursos, ou sei lá, dá um jeito. Aquela trajetória que eu tinha construído na $F$ tinha sido bem mais tranquila né (PROFESSOR B, p. 5-6, grifos nossos).

Apesar dos conflitos iniciais, aos poucos, a partir do empenho, do trabalho e da ética, o professor B conquistou o seu espaço dentro da instituição, algo que fortaleceu a sua autonomia como professor.

(...) enfim passou aquele tempo e nós que éramos os professores novos iniciamos o Curso de Bacharelado em Administração que começou em 2015, agora em 2017 tá na terceira turma já e foi um curso que acabou tomando muita visibilidade e eu acabei pegando várias disciplinas neste curso e ai eu comecei a gostar bastante de trabalhar no curso. Eu fui entrando numa normalidade, eu passei uma época ruim no início, mas depois eu consegui conquistar aquele espaço né, junto ao curso de administração. Daí quando eu me inseri bem no curso de administração eu comecei a gostar muito mais do que eu tava fazendo e aí que eu comecei a ter uma experiência melhor no trabalho. E ai eu tenho uma relação muito forte com os alunos, o curso acabou ganhando notoriedade, ele hoje tem uma concorrência bem grande e todo mundo quer trabalhar nesse curso (PROFESSOR B, p. 6-7, grifos nossos).

Nas palavras de Imbernón (2011), “o professor e as condições de trabalho em que exerce sua profissão são o núcleo fundamental da inovação nas instituições educativas" (p. 21), mas talvez o impasse não esteja apenas nos sujeitos docentes, e sim nos processos e nas relações que são construídas e estabelecidas no ambiente institucional. O professor, segundo o autor, não deveria ser alguém que desenvolve ou implementa tarefas prescritas, mas deveria ser um profissional que participa criticamente do processo de inovação e mudança, intervindo no seu próprio contexto, a partir de um processo dinâmico, flexível e compartilhado. "Tudo isso 
implica considerar o professor como um agente dinâmico cultural, social e curricular" (p. 22) que, em colaboração com os colegas, possa ter autonomia para "tomar decisões educativas, éticas e morais" (p. 22, grifos do autor).

Para que ocorra inovações e mudanças nas instituições educativas, Imbernón (2011) discute a construção de um protagonismo institucional coletivo, em que é necessário pensar em uma concepção de instituição e de formação "(...) como uma organização mais autônoma, entendida como autonomia compartilhada por todos que intervêm no processo educativo" (p. 23) e não como algo competitivo ou determinado por um sistema inflexível de hierarquias. Uma organização capaz de entender que a verdadeira mudança precisa passar por dentro das instituições e não pode ser proposta sem que se construa uma nova forma de perceber as relações sociais, profissionais e educativas.

Assim, "ser professor hoje é viver intensamente o seu tempo com consciência e sensibilidade", pois o seu compromisso não é só transformar a informação em conhecimento, mas também formar pessoas - com uma pluralidade de saberes, sentimentos, contextos e histórias. E formar não no sentido de treinar o educando para o desempenho de destrezas, como tão bem define Freire (1996), mas formar para que sejam capazes de amar, de sonhar, de pensar e de transformar. "Eles fazem fluir o saber (...) porque constroem sentido para a vida das pessoas e para a humanidade e buscam (...) um mundo mais justo, mais produtivo e mais saudável para todos. Por isso eles são imprescindíveis" (GADOTTI, 2003, p. 17).

\section{CONSIDERAÇÕES FINAIS}

É possível afirmar, a partir do desenvolvimento da pesquisa, que a docência se constitui nos percursos de vida e de formação, nos modos de escrita de si e no entrelaçar das tramas, por meio do "tear biográfico". Tramas que marcam histórias singulares e que, ao mesmo tempo, são atravessadas por uma pluralidade de contextos, memórias e identidades. Tramas que, ao serem entrelaçadas, produziram tecituras - representações, sentidos e saberes - que, nesse trabalho, não são entendidas como aspectos fragmentados, mas sim como aspectos que se articulam no movimento de narrar a vida, definindo a docência de quatro professores bacharéis egressos do PEG.

A docência como atividade profissional não aparece nas trajetórias como algo planejado, como um desejo de infância ou um sonho de adolescência, mas como algo que foi sendo construído nos próprios percursos dos professores. As narrativas de vida indicaram que a opção pela docência foi sendo alinhavada por representações pré-concebidas no meio familiar, 
no processo de escolarização e no percurso acadêmico. Escolhas que foram impulsionadas por diferentes aspectos: pelas marcas deixadas por alguns professores; pela influência de pessoas significativas; pela busca de estabilidade financeira; pela participação em atividades extracurriculares e pela experiência do Estágio Supervisionado - que apontaram a docência como um movimento desafiador e interessante.

As narrativas de vida revelaram ainda a construção de sentidos singulares que definem o ser professor - consciência de inacabamento, que apareceu em diferentes momentos das trajetórias quando os professores reconheceram que para ser professor é preciso estar disposto a buscar novos conhecimentos, estar em constante atualização e em permanente busca; (auto)formação permanente, que ficou definida quando os professores relataram sobre a importância da formação pedagógica e de refletir constantemente, individual e coletivamente, sobre a prática, sobre as aulas e sobre o processo de avaliação; autoconhecimento, quando surgiu a reflexão sobre a importância do professor conhecer a si mesmo para melhor compreender o outro e suas ações; compartilhamento de experiências, com diferentes pessoas, contextos e práticas; movimentos, que definiram o professor como alguém que precisa incentivar o pensamento crítico, a formação humana e a busca por uma sociedade melhor e mais justa. O professor como alguém que precisa construir elos e mostrar que tudo no mundo está conectado - pessoas, contextos e sociedade; transformações, de pensamentos, conhecimentos, pessoas e do próprio sistema de ensino; e a busca por diferentes sonhos, dentre eles o sonho de ser educador e não só professor.

A pesquisa aponta para algumas especificidades e marca aspectos diferenciais no processo formativo e na construção da docência dos professores bacharéis envolvidos nesse estudo. Essas singularidades podem ser percebidas na reconstrução das trajetórias individuais, bem como no capítulo em que dialogamos com as tecituras que constituem a docência.

A seguir, destacamos, em linhas gerais, alguns aspectos que podem marcar um novo perfil profissional dos professores bacharéis que atuam na docência nos contextos da Educação Profissional e do Ensino Superior: professora bacharela que, diante da complexidade da educação, "desenha" uma engrenagem para definir o professor, para mostrar que tudo no mundo está conectado e que, pelo "movimento" da engrenagem, nós professores, alunos e sociedade - podemos fazer diferente e participar de um processo mais amplo de transformação da educação; professora bacharela que acredita nas potencialidades do ser humano e na esperança como caminho para transformar a educação; professores bacharéis que compreendem a profissão como projeto de vida, de educação e de sociedade; professores bacharéis que reconhecem a importância da formação humana para a construção 
de uma sociedade melhor e mais justa; professores bacharéis que se preocupam com o meio ambiente, com as relações interpessoais e com os processos de emancipação humana; professores bacharéis que reconhecem a importância de falar em solidariedade no mundo contemporâneo; professores bacharéis que assumem um compromisso político, social e cultural com a formação profissional e cidadã dos estudantes; professores bacharéis que ressignificaram alguns saberes, mas também produziram outros próprios; professores bacharéis que compreendem a importância da formação pedagógica no processo de qualificação profissional; professores bacharéis que se reconhecem como seres inacabados e compreendem a docência como um processo permanente de buscas e desafios.

Nesse sentido, as discussões que foram sendo alinhavadas até o momento, integradas e a partir das narrativas dos professores bacharéis, retomam algumas ideias propostas por Imbernón (2011, p. 12), sobre a necessidade de renovação da instituição educativa e redefinição da profissão docente, no sentido de pensar em novos conhecimentos pedagógicos, científicos e culturais necessários à docência. "Em outras palavras, a nova era requer um profissional da educação diferente". Alguém que compreenda a especificidade dos contextos; que tenha uma visão do ensino não apenas como algo técnico; que analise o conhecimento como algo que está em construção; que reconheça a educação como um compromisso político, ético e moral; que entenda a importância do trabalho colaborativo; enfim, que valorize todos esses aspectos como fatores fundamentais na construção do conhecimento profissional dos professores e, consequentemente, no processo construtivo da docência. Todos esses aspectos e tantos outros que foram problematizados ao longo do estudo, indicam a necessidade de (re)construção, transformação e novas formas de ver e se relacionar com a educação - a partir de dimensões mais humanas, solidárias e sensíveis às relações interpessoais.

\section{Referências}

ALARCÃO, Isabel. Prefácio. In: ABRAHÃO, M. H. M. B. (Org.). Identidade e vida de educadores rio-grandenses: narrativas na primeira pessoa (... e em muitas outras). Porto Alegre: EDIPUCRS, 2004. p. 7-13.

ALVES, Rubem. Conversas com quem gosta de ensinar. Campinas, SP: Papirus, 2000.

ANTUNES, Helenise Sangoi. Ser aluna, ser professora: uma aproximação das significações sociais instituídas e instituintes construídas ao longo dos ciclos de vida pessoal e profissional. 2001. Tese (Doutorado em Educação) - Universidade Federal do Rio Grande do Sul, Porto Alegre, RS, 2001. 
BAUER, Martin W. GASKELL, George. Pesquisa qualitativa com texto, imagem e som: um manual prático. 9. ed. Petrópolis, RJ: Vozes, 2011.

BOLÍVAR, Antonio. "De nobis ipsis silemus": epistemología de la investigación biográficonarrativa en educación. Revista Electrónica de Investigación Educativa. v. 4, n. 1, 2002, p. 40-65. Disponível em: $<$ http://www.redalyc.org/articulo.oa?id=15504103 $>$. Acesso em: 03 jun. 2016.

Las historias de vida y construcción de identidades profesionales. In: ABRAHÃO, M. H. M. B.; FRISON, L.; BARREIRO, C. (Org.). A nova aventura (Auto)biográfica. Tomo I. Porto Alegre: EDIPUCRS, p. 251-287, 2016.

BOLÍVAR, Antonio; DOMINGO, Jesús; FERNÁNDEZ, Manuel. La investigación biográfico-narrativa em educación: enfoque e metodologia. Madrid: La Muralla, S. A., 2001.

BOLZAN, Doris Pires Vargas; ISAIA, Silvia Maria de Aguiar. Pedagogia universitária e aprendizagem docente: relações e novos sentidos da professoralidade. Revista Diálogo Educacional. Curitiba, v. 10, n. 29, p. 13-26, jan./abr. 2010. Disponível em: $<$ https://periodicos.pucpr.br/index.php/dialogoeducacional/article/viewFile/3043/2971>.

Acesso em: 16 jun. 2018.

BRUNER, Jerome. A cultura da educação. Porto Alegre: Artmed Editora, 2001.

BRUNER, Jerome. Realidad mental, mundos posibles. Barcelona: Gedisa, 1988.

DELORY-MOMBERGER, Christine. A condição biográfica: ensaios sobre a narrativa de si na modernidade avançada. Natal: EDUFRN, 2012a.

DELORY-MOMBERGER, Christine. A pesquisa biográfica em educação: desafios e perspectivas. In: SOUZA, E. C. de (Org.). Educação e Ruralidades: memórias e narrativas (auto)biográficas. Salvador: EDUFBA, 2012b, p. 181-200.

DELORY-MOMBERGER, Christine. Biografia e educação: figuras do indivíduo-projeto. Tradução de Maria da Conceição Passegi, João Gomes da Silva Neto, Luis Passegi. - Natal, RN: EDUFRN, São Paulo: Paulus, 2008a.

DELORY-MOMBERGER, Christine. Prefácio. In: PASSEGI, Maria da Conceição (Org.). Tendências da pesquisa (auto)biográfica. Natal, RN: EDUFRN; São Paulo: Paulus, 2008b.

DOLWITSCH, Julia Bolssoni. Tecendo histórias... entrelaçando narrativas: tecituras que constroem a docência de professores bacharéis. Tese (Doutorado em Educação) - Programa de Pós-Graduação em Educação, Centro de Educação, Universidade Federal de Santa Maria. Santa Maria, RS, p. 269. 2018.

DOMINICÉ, Pierre. O processo de formação e alguns dos seus componentes relacionais. In: NÓVOA, António; FINGER, Mathias (Org.). O método (auto)biográfico e a formação. Natal, RN: EDUFRN; São Paulo: Paulus, 2010b, p. 81-95. 
FREIRE, Paulo. Educação como prática da liberdade. 23. ed. Rio de Janeiro: Paz e Terra, 1999.

FREIRE, Paulo. Pedagogia da Autonomia: saberes necessários à prática educativa. 37. ed. São Paulo, Paz e Terra, 1996.

FREIRE, Paulo. Pedagogia do Oprimido. $17^{\circ}$ edição. Rio de Janeiro: Paz e Terra, 1987. 110p.

FREIRE, Paulo. Professora sim, tia não. São Paulo: Olho d'agua, 1997.

GADOTTI, Moacir. Boniteza de um sonho: ensinar-e-aprender com sentido. Novo Hamburgo: Feevale, 2003, 80p.

GARCÍA, Carlos Marcelo. Formação de Professores - Para uma mudança educativa. Porto - Portugal, Porto Editora, 1999.

HUBERMAN, Michaël. O ciclo de vida profissional dos professores. In: NÓVOA, A. (Org.) Vidas de professores. Porto: Porto Editora. 2000. p. 31- 62.

IMBERNÓN, Francisco. Formação docente e profissional: formar-se para a mudança e a incerteza. São Paulo: Cortez, 9. ed., 2011.

MORÉS, Andréia. Educação superior e processos de ensino e aprendizagem em Ead: os casos UCS e UFRGS. Conjectura: filosofia e educação, Caxias do Sul, v. 18, n.1, p. 72-86, jan./abr. 2013.

MOSÉ, Viviane. A escola e os desafios contemporâneos. 2. ed. Rio de Janeiro: Civilização Brasileira, 2013. 336p.

SOARES, Sandra Regina; CUNHA, Maria Isabel da. Formação do Professor: a docência universitária em busca de legitimidade. Salvador: EDUFBA, 2010, 134 p.

SOUZA, Elizeu Clementino. O conhecimento de si: estágio e narrativas de formação de professores. Rio de Janeiro: DP\&A; Salvador, BA: UNEB, $2006 \mathrm{~b}$.

SOUZA, Gláucia de. Tecelina. Porto Alegre: Editora Projeto, 2007.

TARDIF, Maurice. Saberes docentes e formação profissional. 5.ed. Petrópolis: Vozes, 2002.

TARDIF, Maurice; LESSARD, Claude; GAUTHIER, Clermont. Formação dos professores e contextos sociais. Porto, Portugal: Rés editora, 2001.

VEIGA, Ilma Passos Alencastro. Formação de professores para a educação superior e a diversidade da docência. Revista Diálogo Educacional. Curitiba, v. 14, n. 42, p. 327-342, mai./abr. 2014.2 Disponível em: $<$ https://periodicos.pucpr.br/index.php/dialogoeducacional/article/view/6515 $>$. Acesso em: 16 jun. 2018. 